\title{
BEYOND POSITIVISM: FUZZY SET QUALITATIVE COMPARATIVE ANALYSIS AND PRAGMATIST RESEARCH
}

\section{MÁS ALLÁ DEL POSITIVISMO: UN ANÁLISIS CUALITATIVO COMPARADO DE CONJUNTOS DIFUSOS Y UNA INVESTIGACIÓN PRAGMÁTICA}

\section{PABLO GARCÉS VELÁSTEGUI*}

Recibido 15 de mayo del 2016 Aceptado 10 de agosto del 2016

* This paper has benefitted from the contributions of many colleagues. I am particularly thankful to the Universidad Andina Simón Bolívar (Quito) as I was able to carry out this research project during my time there as a researcher. Any errors therein are my own. All the usual disclaimers apply. 



\title{
BEYOND POSITIVISM: FUZZY SET QUALITATIVE COMPARATIVE ANALYSIS AND PRAGMATIST RESEARCH
}

\author{
MÂS ALLÂ DEL POSITIVISMO: UN ANÁLISIS \\ CUALITATIVO COMPARADO DE CONJUNTOS DIFUSOS \\ Y UNA INVESTIGACIÓN PRAGMÁTICA
}

\section{PABLO GARCÉS VELÁSTEGUI}

KEY WORDS: Pragmatism, positivism, qualitative comparative analysis, fuzzy sets, qualitative methods.

PALABRAS CLAVES: Pragmatismo, positivismo, análisis cualitativo comparado, conjuntos difusos, métodos cualitativos.

\begin{abstract}
The literature questioning positivist research in the social sciences is increasing. One promising alternative, which has been gaining momentum, is pragmatism. This discussion, however, has been carried out mainly at the level of the philosophy of (social) science. Consequently, this paper seeks to contribute to the discussion on methods and puts forward Fuzzy Set Qualitative Comparative Analysis (fsQCA) as a research method useful for pragmatist

inquiry. Beyond the quantitative-qualitative divide, fSQCA is a set theoretical method that: i) can capture concept differences both in terms of kind (qualitative) and degree (quantitative); and, ii) focuses on multiple conjunctural causation. That is, it considers cases leading to an outcome as consisting of conditions (conjunctural causation). Moreover, different combinations of these conditions can lead to the same outcome (equifinality). Finally, the presence or
\end{abstract}


absence of an outcome is explained by different reasons, not just the presence or absence of a condition (asymmetri- cal causality). As such, it moves beyond positivism and can be a fruitful tool for pragmatist research.

\section{RESUMEN}

La literatura que cuestiona la investigación positivista en las ciencias sociales está creciendo. Una alternativa prometedora, que está ganando ímpetu, es el pragmatismo. Esta discusión, no obstante, se ha llevado a cabo principalmente en el nivel de la filosofía de la ciencia (social). Consecuentemente, este papel busca contribuir en la discusión de métodos y propone al Análisis Cualitativo Comparado de Conjuntos Difusos (fsQCA) como un método de conjunto que i) puede capturar diferencias conceptuales tanto en términos de tipo (cualitativas) como en grado (cuantitativas); y, ii) se enfoca en la causalidad coyuntural múltiple. Es decir, considera que casos que generan un resultado están compuestos por condiciones (causalidad coyuntural). Además, diferentes combinaciones de estas condiciones pueden generar el mismo resultado (equifinalidad). Finalmente, la presencia o ausencia del resultado se explica de distintas maneras, no solamente la presencia o ausencia de una condición (causalidad asimétrica). Por tanto, va más allá del positivismo y puede ser una herramienta útil para la investigación pragmatista.

\section{INTRODUCTION}

The conduct of inquiry in the social sciences has been dominated by positivism. The latter focuses on the quest for certainty as the basis for "true" knowledge. This has also been referred to as Cartesian anxiety (Bernstein, 1983). This is perhaps most notable in the primacy of quantitative methods. In fact, the divide between quantitative and qualitative methods can arguably be attributed to it. This has permeated qualitative research as well. The most influen- tial effort to enhance the rigorousness in this area suggests that qualitative methods have to be more positivist (see King, Keohane \& Verba, 1994).

However, positivism is far from uncontested. There is a growing body of literature questioning the philosophical wagers it makes and their implications for research in the social sciences (see e.g. Jackson, 2011). Moreover, such efforts have proposed interesting alternatives to the positivist orthodoxy. One 
ReVISta PUCE. ISSN 1390-7719.Núm. 103. 3 de MAYO DE 2016 -

such alternative that is gaining influence is pragmatism. Pragmatism moves beyond positivism by departing from action, neither from reason nor things. As such, it abandons the Cartesian anxiety and takes the contingent nature of knowledge seriously.

This discussion has been mainly addressed at the level of the philosophy of science. At the level of methods, the debate has been less prolific. In this sense, this paper seeks to contribute to the debate at the level of methods and proposes Fuzzy Set Qualitative Comparative Analysis as a promising tool to move beyond positivism and one that can be put to good use by pragmatist research. In order to so, the first section discusses, however briefly, the main tenets of positivism and pragmatism. The second section, introduces both fuzzy sets and Qualitative Comparative Analysis in details. The fourth section argues in favor of the affinity of fsQCA with pragmatism. The final section concludes.

\section{BEYOND POSITIVISM: PRAGMATISM}

\section{Positivism, in brief}

Positivism encompasses a particular approach to inquiry. It is difficult to summarize positivism given its complex history and even conflicting components. However, broadly conceived, it is a philosophy of science that seeks to emulate the physical or natural sciences in the study of the social world, given the great progress acquired by the former in explaining, predicting, and even controlling the natural world. This has at least two important philosophical implications, one ontological, one epistemological. The ontological position is that there is a world "out there", that the world exists outside of human cognition (Krauss, 2005). Concomitantly, positivism entails the epistemological position that that world is knowable and true knowledge can only be that which mirrors that independent-from-the-mind world (Krauss, 2005). The former is called ontological realism, the latter correspondence theory of truth (Friedrichs \& Kratochwil, 2009).

This approach has important interrelated implications for the conduct of inquiry. The first is the emphasis on objectivity. Positivism finds its origins with the intention of many philosophers, particularly August Comte, to rid philosophy of metaphysics (Kaboub, 2008). Early positivists sought to treat philosophy itself as a science. In order to do so, they argued for an elimination of all that cannot be known with absolute certainty and thus 
be considered as knowledge claims (Caldwell, 1994). That is, positivism separates objectivity from subjectivity, facts from values, giving the status of knowledge claims solely to the former. Indeed, themes previously regarded as philosophical, namely metaphysics, ethics and aesthetics, were deemed meaningless because they either cannot be translated into logically correct form or there are no empirical grounds to establish their truth or falsity (Waugh \& Ariew, 2008).

A second implication is the models used to arrive at knowledge claims, namely the covering law models. By the early twentieth century, a group of philosophers, later known collectively as the Vienna Circle, worked further on the development of positivism. Although their label changed from logical positivists to logical empiricists, their agenda was for the most part the same. As in the physical sciences, these positivists believed the social world consists of regularities that could be unveiled if only the right approach were employed. The models argued for, called the 'covering law models', exhaust the universe of legitimate explanation in the physical sciences and nearly so in the social sciences (Caldwell, 1994). These models were the deductive-nomological and the inductive-probabilistic models. The first refers to the notion that the social world is governed by timeless immutable laws that could be uncovered ${ }^{1}$ (Caldwell, 1994). The second denotes those statements in science that refer to highly probable statistical laws rather than universal ones² (Caldwell, 1994).

By the same token, a third implication is the falsifiability and empirical verification as the only way to set a demarcation criterion for separating science from non-science and, thereby, grow knowledge. According to Popper (2002a), scientific theories begin as bold conjectures and they attain the status of scientific if they pass severe critical tests, that is, if they are falsifiable 3 . Those theories that can be more severely tested, those that forbid more, are regarded as having higher empirical content (Popper 2002b). Those that survive repeated tests are considered corroborated. For Popper, content and probability vary inversely, thus corroborated theories are less probable. Consequently, refutation and

${ }^{1}$ Erasmus University Rotterdam. Institute of Social Studies. Rotterdam. (garcesvelastegui@iss.nl)

2 "The deductive-nomological (D-N) model, developed by Hempel and Oppenheim, requires that the explanandum statements be logically deducible from the explanans, which includes statements expressing initial conditions and at least one general law of universal form" (Caldwell, 1994: 54).

${ }^{3}$ Popper insists on his concept of falsifiability as useful for distinguishing between scientific and non-scientific statements, not just between meaningful and meaningless statements. He admitted that there could be non-scientific meaningful statements (Caldwell, 1994). 
ReVista PUCE, ISSN 1390-7719. Núm, 103, 3 de MAYO De 2016 -

corroboration, not confirmation of theories that have inductive probabilities, is the focus of science, and, importantly, it is the way scientific knowledge grows (Popper, 2002a; 2002b).

Consequently, a final implication from the discussion above is the belief in the unity of science. Since inquiry in both the physical and the social sciences can be furthered by dint of the same assumptions and methods, there is no significant difference between them (Caldwell, 1994). This led positivists to assert that the natural and social are in fact one science.

Thus, positivism's legacy for the social sciences in general can be attested in the pervasiveness of four tenets ${ }^{4}$ : i) a strict fact/value separation; ii) the assumption of regularities in the social sciences that warrant the use of the cover law models; iii) empirical verification and falsification as the way to further inquiry; and, iv) the unity of science (Smith, 1996).

\footnotetext{
${ }^{4}$ Although Smith (1996) emphasizes the discipline of international relations, the argument applies more broadly. There is no coincidence that these four points resonate strongly with what scholars like Kolakowski (in Krauss, 2005: 761) have argued are the defining aspects of positivism:"(1) the rule of phenomenalism, which asserts that there is only experience; all abstractions be they "matter" or "spirit" have to be rejected; (2) the rule of nominalism - which asserts that words, generalizations, abstractions, etc. are linguistic phenomena and do not give new insight into the world; (3) the separation of facts from values; and (4) the unity of the scientific method".
}

\section{Pragmatism: beyond positivism}

Pragmatism rejects positivism. Unlike empiricism or rationalism (on which positivism builds), pragmatism does not depart from 'things' or 'reason', respectively, but from 'action' (Kratochwil, 2011). Instead of conceiving inquiry as the process by which a passive mind received knowledge from a world that is unveiled to it, it takes a rather naturalistic approach. According to it, knowledge is the product of the interaction between humans and their environment (Dewey, 1985). In this sense, inquiry takes place as a response of human beings to a problem. In order to solve it, they engage with their environment, manipulating it and testing different hypotheses, until a solution is found that allows them to further human action. Solving a challenge, i.e. generating useful knowledge, is tantamount to a process of adaptation incurred by humans. But this is one in which both the subject and the object are affected by one another (Khalil, 2004). As such, pragmatism seeks to take seriously actual research practices and human cognition. The aspiration of pragmatism has been described as "... a philosophy that is at once naturalist and humanist, a philosophy that fully respects the modern scientific worldview without thereby losing contact with the world of human experience" (Talisse \& Aikin, 2011: 4). 
As a philosophy, pragmatism is critical of the ontological and epistemological implications of positivism. Regarding ontological realism, pragmatism rejects the view that there is a world 'out there' independent from human cognition and that the object known is not affected by the knower (Cochran, 2002). The mind does not observe a world in itself but acts in the world and by so doing it changes it (James, 1977). In fact, it argues that what is known is affected by the prior theories and worldviews of the knower. That is, the observed object is constituted by the observing subject (Kratochwil, 2007). Thus, since there is no 'world out there,', the categories used to understand it do not come from objects but from the mind (Friedrichs \& Kratochwil, 2009).

Moreover, ontological realism fails for reasons specific to the social sciences. Unlike the physical world, the social one is not made out of objects. Social reality, as Weber emphasized, is constituted by intersubjective meaning and value relations (Friedichs \& Kratochwil, 2009). Therefore, social knowledge is based on both explaining (erklären) and understanding (verstehen).

Apropos the correspondence theory of truth, positivism considers as knowledge claims those statements that mirror the world. That is, truth as a property of the world. However, if the world can only be known through the precon- ceptions of the knower, the pursuit of truth and the absolute certainty it brings is useless because there is no yardstick against which statements can be tested (Friedrichs \& Kratochwil, 2009).

Additionally, in the case of the social sciences, correspondence theory of truth poses particular challenges. As the discussion in the previous section shows, the positivist quest for certainty establishes a binary logic: something either is or is not (Kratochwil, 2007), statements are true/false. This can hardly apply to the social sciences where yes or no answers are quite scarce. In fact, as Friedrichs and Kratochwil (2009: 705) point out, the category of undecidable questions, a category that supposedly cannot exist, is "embarrassingly large".

Thus, pragmatism is a philosophy that is concerned with practical consequences ${ }^{5}$. It places the locus of inquiry

${ }^{5}$ The pragmatic maxim stated by Peirce (1905: 171, emphasis in the original) stated: "Consider what effects that might conceivably have practical bearings you conceive the object of your conception to have. Then your conception of those effects is the WHOLE of your conception of the object". Later this view would be extended, in an anti-positivist manner, by William James (1977: 377-378) who asserts: "To attain perfect clearness in our thoughts of an object, then, we need only consider what conceivable effects of a practical kind the object may involve what sensations we are to expect from it, and what reactions we must prepare. Our conception of these effects, whether immediate or remote, is then for us the whole of our conception of the object, so far as that conception has positive significance at all". 
ReVISta PUCE. ISSN 1390-7719.Núm. 103. 3 de MAYO DE 2016 -

on addressing actual problems creatively and accepting the incomplete nature of knowledge. This points to the two main differences between positivism and pragmatism. Instead of ontological realism, pragmatism proposes epistemological instrumentalism. In lieu of the correspondence theory of truth, it argues for a consensus theory of knowledge.

Epistemological instrumentalism ${ }^{6}$ emphasizes pragmatism's problem oriented nature and its concern with useful knowledge. This means, that research should serve a clear, explicit purpose, but not any purpose. As Friedrichs and Kratochwil (2009) argue, the purpose of social inquiry is to contribute to a better understanding of complex phenomena, to our orientation in the social world, to address relevant social problems.

Consensus theory of knowledge, in turn, has a twofold implication. First, pragmatism emphasizes the contingent nature of knowledge. The positivist quest for certainty and the approximation to the 'truth' is rejected. For Dewey (in Cochran, 2002), laws are not universal and immutable, solely waiting to be discovered. Instead (if laws are to be considered at all), they are more or less useful generalizations that work in a certain situation until they are found faulty and the search for new ones begins again.

${ }^{6}$ This denomination reflects Dewey's own preferences regarding his theory of knowledge, which he called instrumentalism (Quinton, 2010).
Second, it recognizes that knowledge is socially produced (Quinton, 2010). Since knowledge generation is committed to the methods and standards shared by epistemic communities, this entails that knowledge claims are always put to their consideration and debate (Dewey, 2008b). It is these communities of practice that help define the problems and critically assess the results of research instead of simply lifting the veil of nature. Nevertheless, in order to avoid academic self-encapsulation, it is useful to involve various disciplines in the process and even relevant (social) stakeholders (Friedrichs \& Kratochwil, 2009).

Thus, the critical element of the epistemological project is kept. Kant's court, which he argues is reason itself, is replaced by communities of scholars (Kratochwil, 2011). Each community provides its own tribunal and evaluates the appropriateness of its own practices and methods. Thus, instead of objectivity, pragmatism favors agreement ${ }^{7}$ (Rorty, 1979). Additionally, different communities utilize different methods, which widen the methodological scope to a plurality of tools and resources. Finally, pragmatism recognizes that normativi-

7 "For pragmatists, the desire for objectivity is not the desire to escape the limitations of one's community, but simply the desire for as much intersubjective agreement as possible, the desire to extend the reference of 'us' as far as we can". (Rorty in Talisse \& Aikin 2011: 4) 
ty is ubiquitous in all of experience and, thus, there is no distinct dichotomy between facts and values (Bacon, 2012). If values are not equated with 'ethics', scientific assessments are value-laden because they entail epistemic values such as 'coherence', 'simplicity' or 'reasonableness', which cannot be separated into descriptive and normative parts (Putnam, 2002).

Finally, an additional implication of pragmatism becomes clear, for failure in the pursuit of certainty of the positivist project does not mean a turn towards relativism, let alone nihilism (Kratochwil, 2011). The answer to the anxiety created by the unrealistic expectations of positivism in its quest for certainty is embracing the incomplete and contingent nature of knowledge and increasing the awareness with which inquiry is conducted, so as to generate with useful, lasting knowledge. How can pragmatism be put to good use empirically? The next section is dedicated to providing a plausible answer.

\section{Beyond positivism: Fuzzy Set Qualitative Comparative Analysis}

In this section, I make the case for fuzzy set qualitative comparative analysis (fsQCA) not only as a promising non-positivist method for social science research, but particularly in the study of causation.

\section{Fuzzy set theory and logic}

Social science concepts can be usefully understood as fuzzy sets. The reason is twofold: relations and double variation. Regarding the former, this is mainly due to the fact that set-theoretic relationships (i.e. a set being a subset or a superset of another) are ubiquitous in social science discourse (Ragin, 2000). In this sense, set-theoretic methods can shed light on what would be regarded simply as correlations in conventional methods, particularly when their direction is unclear. Apropos the latter, social science concepts can be expressed qualitatively in theoretical discourse, but allow for variation in degree (Ragin, 2000). Fuzzy sets enable to capture both, qualitative as well as quantitative variation, respectively. However, fuzzy sets are particularly useful for certain kinds of concepts: those intrinsically complex and intrinsically vague (Chiappero-Martinetti, 2008).

According to Chiappero-Martinetti (2008, p. 271), intrinsic complexity "...pertains to the nature of a given phenomenon, and can be partially or fully reflected in the way in which the phenomenon has been conceived and conceptualized". Intrinsically complex concepts are multifaceted multidimensional concepts composed of many interrelated elements for which, generally, the whole cannot be fully understood by 
ReVista PUCE. ISSN 1390-7719.Núm, 103. 3 de MAYO de 2016 -

separate analysis of its components (e.g. well-being, democracy, war). Intrinsic vagueness, in turn, "... refers to the nature of a given concept or phenomenon" (Chiappero-Martinetti, 2008: 276). These concepts are characterized by the absence of a universal definition and their connotation of different things depending on the situation (e.g. poverty, autonomy). Three criteria can help identify intrinsically vague concepts, which are characterized by: i) having borderline cases; ii) not having sharp boundaries in membership; and iii) being susceptible to Sorites paradoxes $^{8}$ (Keefer and Smith in Qizilbash, 2003). Crucially, vagueness is to be distinguished from inaccuracy, imprecision, unspecificity or underspecificity, and semantic ambiguity; rather it is better associated with indeterminacy and fuzziness (Chiappero-Martinetti, 2008).

In practice, perhaps it can be useful to relate the discussion to a simpler

\footnotetext{
${ }^{8}$ Chiappero-Martinetti (2008: 276) uses the following passage from Williamson in order to exemplify the sequence of questions in which Greek paradoxes were presented: "Does one grain of wheat make a heap? Do two grains of wheat make a heap? Do three grains of wheat make a heap? ... Do ten thousand grains of wheat make a heap? It is to be understood that the grains are properly piled up, and that the heap must contain reasonably many grains. If you admit that one grain does not make heap, and are unwilling to make a fuss about the addition of any single grain, you are eventually forced to admit that ten thousand grains do not make a heap."
}

version (subset) of fuzzy sets. The most basic, and initial, approach has been to assign scores of one (1) for membership and zero (0) for non-membership in a given set. These are referred to as crisp sets and denote neatly two qualitatively different states; for example, in the analysis of literacy, the set of literate people, a score of 1 would be assigned to literate individuals and a score of 0 to non-literate individuals. However, as can become evident in this very example,"... many social science concepts are dichotomous in principle, but that their empirical manifestations occur in degrees" (Schneider \& Wagemann, 2012: 14). That is, many concepts in the social sciences are a matter of degree, not all or nothing conditions, which simply cannot be captured by a black and non-black conception of the world.

Therefore, a method more sensitive to that partial membership is needed. Fuzzy set theory offers a plausible alternative to the dichotomous custom since it is a mathematical framework that allows the treatment of categories with partial membership or degrees (Smithson \& Verkuilen, 2006). In turn, "... a fuzzy set is a continuous set that has been carefully calibrated to indicate degree of membership" (Ragin, 2000: 154). Thus, fuzzy sets define both qualitative states (full membership $=1$, full non-membership $=0$ ) and the level of membership in 
between them ${ }^{9}$. Therefore, the fuzziness does not derive from imprecise empirical information, but from non-sharp conceptual boundaries (Schneider \& Wagemann, 2012).

Thus, fuzzy sets can capture qualitative distinctions among cases, like crisp sets do, but also add differences in degree. Hence, fuzzy sets can be used together with crisp sets. The virtues of fuzzy sets, nevertheless, also entail complications. The translation ${ }^{10}$ of the data into membership scores becomes more precise, but this precision is more demanding. Unlike variables in conventional variable-oriented research (i.e. mostly positivist), which are calibrated according to measures of central tendency and dispersion (Ragin, 2000), fuzzy sets are bound to external standards that have face validity (Ragin, 2008). It is an exercise of carefully specifying qualitative anchors to each breakpoint on continua (Ragin, 2000; 2008). That is, they answer to an explicit rationale based on theoretical or substantial knowledge (Ragin, 2000).

${ }_{9}^{9}$ Fuzzy sets should not be confused with ordinal scales. The latter are rankings of categories arrayed relative to each other, often with no reference to external criteria in order to link categories to degree of membership (Schneider \& Wagemann, 2012; Ragin, 2000; 2008).

10 Referring to this process as a translation is purposeful. It best captures the exercise at hand, namely interpreting raw data into intelligible and meaningful information. The tool that facilitates this endeavor is the theory.
Hence, fsQCA demands a high degree of theoretical-methodological awareness. The reason is at least threefold. First, due to the fact that by and large it works outside the statistical template and as such, the measure of uncertainty falls closer to judgments of the researcher than in statistical methods, which have standardized methods for those measures (Berg-Schlosser et al, 2009). Second, because the focus on outcomes requires the selection of pertinent cases for analysis. That is, only cases that present the outcome are selected. In conventional positivist approaches, this is malpractice known as selecting on the dependent variable (see King at al, 1994). Third, and related to the latter, given that revisiting every step is often required (and advised) in light of new insights, populations are not fixed. In fact, the selection of cases, the data collection, and analysis is in constant revision and reconsideration. This is another practice frowned upon by rigid positivism, but iteration in the back and forth between theory and evidence is required by fsQCA en order to enhance precision.

\section{Qualitative Comparative Analysis (QCA)}

QCA finds its origins in the pioneering work in comparative analysis carried out by John Stewart Mill. Particularly, his method of agreement and 
ReVISta PUCE. ISSN 1390-7719.Núm. 103. 3 de MAYO DE 2016 -

method of difference. Mill (1967, p. 390) describes the method of agreement in these terms: "If two or more instances of the phenomenon under investigation have only one circumstance in common, the circumstance in which alone all the instances agree is the cause (or effect) of the given phenomenon." Regarding the method of difference, he posits:

If an instance in which the phenomenon under investigation occurs, and an instance in which it does not occur, have every circumstance in common save one, that one occurring only in the former; the circumstance in which alone the two instance differ, is the effect, or the causes, or an indispensable part of the cause of the phenomenon (Mill, 1967: 391).

These proposals have intuitive logic; however, they are of rather difficult application. They share the purpose of comparing cases to expose shared causal relationships by eliminating all other possibilities. Nonetheless, Mill's procedures seem to be extreme, since they seek to find a single cause (or effect) by controlling all others and the environment as well (Berg-Schlosser et al, 2009). Considering this, Mill put forward another proposal that sought to combine the two methods and called it Joint Method of Agreement and Difference or Indirect Method of Difference, which consisted of a double application of the Method of Agreement ${ }^{11}$. Even this procedure poses problems, particularly in the social sciences, given their rather stark positivist assumptions regarding cause and effect (Berg-Schlosser et al, 2009). As such, they appear overly deterministic and mechanistic. However, they constitute a valuable contribution to inquiry by suggesting a systematic process through which irrelevant elements can be eliminated. In the search for causation, it is this valuable insight that QCA borrows to determine the conditions of occurrence for an outcome (Berg-Schlosser et al, 2009).

Set theoretic methods in general and QCA in particular, provide an alternative to do research in the social sciences, beyond the quantitative-qualitative divide. First, as mentioned above, social science concepts are represented as sets. The data used are translated into membership scores of the cases according to those sets, denoting qualitatively different states (i.e. member vis-à-vis non member). Second, cases are conceived

11 In Mill's (1967: 396) words: "If two or more instance of which the phenomenon occurs have only one circumstance in common, while two or more instances in which it does not occur have nothing in common save the absence of that circumstance, the circumstance in which alone the two sets of instances differ, is the effect, or the cause, or an indispensable part of the cause, of the phenomenon". 
as configurations. Third, QCA focuses on diversity, understood as encompassing both complexity and generality. It neither regards populations as homogenous and fixed nor privileges the specificity of individual cases. As such, it works with intermediate-sized $\mathrm{N}$ studies and allows moderate generalizations (Ragin, 2000).

Additionally, set-theoretic methods favor the study of causation (in a non-positivistic manner). They do so by focusing on the sufficient and necessary conditions to produce an outcome. A condition is necessary for an outcome if, and only if, it is present every single time the outcome occurs. That is, the outcome cannot happen without the condition. On the other hand, a condition is sufficient if, and only if, every single time the condition is present, the outcome occurs. In other words, the condition cannot happen without the outcome, but the outcome could result from other conditions (Rihoux \& Ragin, 2009). In brief,

Set theoretic methods are approaches to analyzing social reality in which (a) the data consists of set membership scores; (b) relations between social phenomena are modeled in terms of set relations; and (c) the results point to sufficient and necessary conditions and emphasize causal complexity in terms of INUS [and] SUIN causes $^{12}$ (Schneider \& Wagemann, 2012: 6, emphasis in the original).

In this sense, set-theoretic methods share three main characteristics that distance them from conventional methods used in policy analysis, i.e. quantitative methods and statistical techniques, namely, equifinality, conjunctural causation, and asymmetry. Regarding equifinality, the focus of set-theoretic methods on sufficiency and necessity shows that the identification of a sufficient condition leading to an outcome, entails that there are generally other conditions also sufficient for the same outcome (Schneider \& Wagemann, 2012). That is, there are many pathways to the same outcome.

Moreover, the identification of set relationships may be more complex. QCA rejects additivity, i.e. the assumption that each single cause has an independent isolated effect on the outcome (Berg-Scholsser et al, 2009). It may be the case that single conditions do not show an effect on an outcome, but that they do only together with other conditions. Additionally, no uniformity in causal effects

12 INUS stands for Insufficient but Necessary part of a condition which is itself Unnecessary but sufficient for the outcome. SUIN stands for Sufficient but Unnecessary part of a condition which is Insufficient but Necessary for the result (Schneider \& Wagemann, 2012). 
ReVISta PUCE. ISSN 1390-7719.Núm. 103. 3 de MAYO DE 2016 -

is assumed, quite the opposite. A given condition combined with others may contribute to the outcome, but in a different combination; the same condition can act in detriment to it (Berg-Schlosser et al, 2009). This is known as conjunctural causation. And this combination can ensue in a variety of ways, mixing the sufficient and necessary nature of conditions. That is, multiple conjunctural causation.

Finally, symmetrical causality is rejected in favor of asymmetrical causality. That is, the idea that the presence or absence of the outcome, respectively, is likely to need quite different explanations (Berg-Schlosser et al, 2009). Asymmetry refers to the fact that a set-theoretic approach to concepts entails two separate definitions of concepts when in conventional approaches only one is utilized. From this, it follows that two different sets are required to capture two qualitatively different states. Thus, the causal implication of asymmetry is that the explanation for the occurrence of an outcome cannot be automatically derived from the explanation of its non-occurrence, and vice versa (Schneider \& Wagemann, 2012).

Consequently, QCA is an approach to inquiry that regards an outcome of interest as the result of various specific combinations of different factors. As such, it allows for complex causality under the banner of "multiple con- figurational causation" (Berg-Schlosser et al, 2009). This is a characteristic feature of social science research (Mill, 1967).

\section{fsQCA and pragmatist research}

The sections above have shown how fsQCA can be useful for research in the social sciences in general. This discussion has also argued how the QCA distances itself from positivism at the level of methods. But what about its philosophy of science? More importantly, is it compatible with pragmatism? By answering the latter, the former is also answered, so this section focuses on making the case of fsQCA as a method useful for pragmatist research. To do so, the focus is on i) John Dewey's (one of the most important classical pragmatists) view on Newtonian natural laws; ii) the spirit of pragmatism; and, iii) abduction.

First, from a pragmatist perspective, universal, absolute, and representationally true laws are to be abandoned. This applies, according to Dewey, for the natural and even more so for the social sciences. The justification and explanation for the Newtonian conception of "natural" laws are undermined by pragmatism's fallibilism. Nevertheless, this does not mean that the insights they provide are not useful (Hands, 2004). Similarly, although causation based on necessity and sufficiency, as in the case of QCA, does suggest a law-based ap- 
proach (Tavory \& Timmermans, 2014) in the Newtonian sense, these can also be characterized pragmatically and their insights; therefore, put to good use. To do so, one must acknowledge the absence of laws in the physical sense in the social world and instead focus on its rules, which are the regularities present in this domain (Viskovatoff, 2004). Thus, the conditions identified as leading to an outcome, whether necessary or sufficient (or INUS or SUIN), should not be understood in any nomological sense. Instead, they are to be understood as rules, which are fairly stable evidence of persistence in the social domain (Viskovatoff, 2004). Hence, in the spirit of Deweyan pragmatism, they can be regarded as warranted assertability, that allows a controversial issue to be settled for the time being, until there are reasons to dislodge that settlement.

Importantly, however, this preliminary nature of knowledge is pragmatist. Positivist prudence makes statements revisable only because of accidental or hypothetical grounds. This is because, from that perspective, an unexpected observation can always appear that can challenge the statement. In pragmatism, fallibilism rises from the nature of inquiry as action, and action involves imagination, beliefs, preferences. and interests. From this perspective, statements are invariably underdetermined by empiri- cal evidence, that is, "... no direct appeal to empirical evidence can univocally determine the meaning of a statement or the reality it denotes" (Khalil, 2004: 3). Therefore, the products of inquiry, i.e. statements, are as open to revision as the knower's beliefs, interests and imagination are.

Put tersely, the positivist philosopher tempers his excitement for a statement because of some possible surprises of hidden evidence. In contrast, the transactionist [pragmatist] philosopher tempers his excitement for a statement because it is the product of transaction between the knower (as an actor with beliefs and imagination) and the known (as ends sought in light of the beliefs and imagination). Thus, when the transactionist qualifies statements as tentative, the qualification arises from an understanding of inquiry as action, rather than from some possible encounter with new facts (Khalil, 2004: 3).

Second, the classical pragmatists favored addressing practical problems. Indeed, they sought to bring philosophy to practical concerns. In order to so do, they privileged creativity and plurality in the use of methods (Kratochwil, 2011). 
ReVISta PUCE. ISSN 1390-7719.Núm. 103. 3 de MAYO DE 2016 -

Dewey notably took issue with the onesize-fits-all approach to inquiry established by the positivist "scientific method". Indeed, he stressed that "there is no kind of inquiry which has a monopoly of the honorable title of knowledge" (Dewey in Hands, 2004: 262).

In this sense, some commentators have been emphatic in their understanding of the spirit of pragmatism and its implications for social science:

Those of us who work out of the pragmatic tradition betray that tradition when we pit ourselves, might and main, against allegedly or even actually rival traditions, movements and positions. We honor that tradition when we abandon myths of originary purity and forge alliances, cutting across diverse boundaries (ideological, disciplinary, linguistic, cultural, and national), for the sake of advancing inquiry and enhancing interpretation (Colapietro, 2004: 106).

Finally, QCA shares much with abduction, a pragmatist method for theorizing. Abduction is a pragmatist method that, unlike deduction and induction, seeks to create, not just incrementally accumulate, knowledge. Charles Peirce, its progenitor, argued that this method be- longs in the 'context of discovery'. As opposed to the 'context of justification', the stage in scientific inquiry that focuses on the assessment of theories, the context of discovery is the stage where new theories are generated. According to Peirce, abduction is a part of the three-stage process of scientific inquiry. In the face of unexpected facts, to account for them, hypotheses are invented and generated, which via deduction are explicated, and predictions of experimental consequences are postulated, so that through induction, those hypotheses can be tested (Fann, 1970). As such, he regarded abduction as "only kind of argument which starts a new idea" (Peirce in Queiroz \& Merrell, 2005: 2).

In order to see how fsQCA can be related to abduction, it is useful to follow Tavory and Timmermans (2014) who propose "abductive analysis" as a method that shows how abduction can contribute to theorizing in qualitative research. In brief, their approach follows Peirce's semeiotic theory and focuses on the identification of surprising or unexpected observations based on consequences in action. A pattern is then explored among them accounting for some degree of variation, which is constructed in set-theoretic terms. If such a pattern can be established, then generalization is possible and so is theorization based on causality. In order to achieve this, a 
close back and forth between evidence and theory as well as constant revision of data collected is required. In fact, it is necessary to have a broad and deep theoretical knowledge. Therefore, abduction entails circularity in the process, moving from ideas to evidence iteratively. As such, abduction recovers the organic nature of human cognition, which takes place in hermeneutic circles and is far superior to the attempts made in social science, as it tries to emulate the actual way in which humans being learn and solve problems (Friedrichs, 2009).

These characteristics, their admittedly notorious differences notwithstanding, seem to resonate with QCA. Among the most important are, first, QCA is a set-theoretic method that departs from outcomes, which are arguably analogous to the focus on (practical) consequences. Second, QCA pays close attention to outliers, i.e. observations that appear as surprises or are unexpected from the theoretical perspective of the researcher. This opens the possibility for important insights and perhaps theorization. Finally, fsQCA entails a very precise calibration regarding set membership and close attention to the configurations that form cases. Both processes require constant iteration between theory and evidence to adequately determine causality. This does not mean necessarily that QCA is somehow abductive. Instead, the argument here is that QCA seems to be quite compatible with the spirit of pragmatism and therefore a useful method for pragmatist research.

\section{CONCLUSION}

In the ever richer debate on how to assess knowledge claims, there has been an interesting move from positivist orthodoxy and its (obsession with) absolute certainty. In this context, pragmatism appears as a compelling alternative to carry out research free from the unrealistic expectations derived from the positivist project, i.e. the Cartesian anxiety.

This paper has sought to contribute to this literature at the level of methods. In order to do so, it argued in favor of fuzzy set qualitative comparative analysis as a promising method for pragmatist research. Beyond the quantitative-qualitative divide, fsQCA is a set theoretic method that: i) can capture concepts' differences both in terms of kind (qualitative) and degree (quantitative), and ii) focuses on multiple conjunctural causation. That is, it considers cases leading to an outcome 
ReVista PUCE. ISSN 1390-7719.núm, 103. 3 de Mayo de 2016 -

as consisting of conditions (conjunctural causation). Moreover, different combinations of these conditions can lead to the same outcome (equifinality). Finally, the presence or absence of an outcome is explained by different reasons, not just the presence or absence of a condition (asymmetrical causality).

Hence, fsQCA is a useful method for the social sciences in general and it can be put to good use particularly by pragmatist research. Although an empirical exercise lies beyond the scope of this paper, it is certainly not beyond the efforts of a wider academic community seeking to further inquiry in a transparent, coherent, and more realistic (pragmatist) fashion.

\section{BIBLIOGRAPHY}

Bacon, M. (2012). Pragmatism: an introduction. Cambridge: Polity Press

Berg-Schlosser, D. et al. (2009). "Qualitative Comparative Analysis (QCA) as an Approach." In Rihoux, B. \& Ragin, C. (eds.) Configurational Comparative Methods: Qualitative Comparative Analysis (QCA) and Related Techniques (pp. 1-18). Thousand Oaks, US: SAGE Publications

Bernstein, R. (1983). Beyond Objectivism and Realism: science hermeneutics and praxis. Philadelphia: University of Pennsylvania Press

Chiappero-Martinetti, E. (2008). "Complexity and vagueness in the capability approach: strengths or weaknesses?" In Alkire S., Comim F. \& Qizilibash M, (eds), The capability approach in human development: concepts, applications and measurement (pp. 268-309). Cambridge University Press

Cochran, M. (2002). "Deweyan Pragmatism and Post-Positivist Social Science in IR." Millennium - Journal of International Studies, 31 (1), pp. 525

Colapietro, V. (2004). "Toward a truly pragmatic theory of signs, reading Peirce's semeiotic in light of Dewey's gloss." In Khalil, E. (ed.), Dewey, Pragmatism, and Econom- 
ic Methodology (pp. 102-130). New York: Routledge

Dewey, J. (1985). The Middle Works of John Dewey 1899-1924, Volume 12. Carbondale, US: Southern Illinois University Press

Dewey, J. (2008). The Later Works of John Dewey 1925-1953, Volume 5. Carbondale, US: Southern Illinois University Press

Friedrichs, J. (2009). "From Positivist Pretense to Pragmatic Practice, varieties of Pragmatic Methodology in IR Scholarship." International Studies Review 11(): 645-648

Friedrichs, J. \& Kratochwil, F. (2009). "On acting and Knowing: how pragmatism can advance International Relations research and methodology." International Organization. 63, pp. 701-731

Hands, D. W. (2004). "Pragmatism, knowledge and Economic Science, Deweyan pragmatic philosophy and contemporary economic methodology." In Khalil, E. (ed.), Dewey, Pragmatism, and Economic Methodology (pp. 1-12). New York: Routledge

Jackson, T. (2011). The Conduct of Inquiry in International Relations: philosophy of science and its implications for the study of world politics. London: Routledge
Khalil, E. (2004). "John Dewey, the transactional view and the behavioral sciences." In Khalil, E. (ed.), Dewey, Pragmatism, and Economic Methodology (pp. 1-12). New York: Routledge

King, G., Keohane, R. \& Verba, S. (1994). Designing Social Inquiry: Scientific inference in qualitative research. NJ, US: Princeton University Press

Kratochwil, F. (2007). "Of False Promises and Good Bets: a plea for a pragmatic approach to theory building (the Tartu lecture)." Journal of International Relations and Development, 10, pp. 1-15

Kratochwil, F. (2011). "Ten points to ponder about Pragmatism." In H. Bauer \& E. Brighi (Eds.) Pragmatism in International Relations (pp. 11-25). New York, US: Routledge

Krauss, S. (2005). "Research Paradigms and Meaning Making: A Primer." The Qualitative Report, 10 (4), pp. 758-770

Peirce, C. (1905). "What Pragmatism is." The Monist, 15 (2), pp. 161-181

Popper, K. (2002a). The Logic of Scientific Discovery. New York, US: Routledge

Popper, K. (2002b). Conjectures and Refutations. New York, US: Routledge Qizilbash, M. (2003). "A note on the measurement of poverty and vul- 
ReVista PUCE. ISSN 1390-7719.Núm.103. 3 de MAYO de 2016 -

nerability in the South African context". Journal of International Development, 14: 757-772

Queiroz, J. \& Merrell, F. (2005). "Abduction: between subjectivity and objectivity." Semiotica. 153 (1): 1-7

Quinton, A. (2010). "Inquiry, thought and action: John Dewey's theory of knowledge." In R.S. Peters (Ed.) John Dewey Reconsidered (pp: 1-11). New York, US: Routledge

Ragin, C. (2000). Fuzzy-Set Social Science. London, UK: University of Chicago Press

Ragin, C. (2004). Between Complexity and Parsimony: Limited Diversity, Counterfactual Cases, and Comparative Analysis. Theory and Research in Comparative Social Analysis, Department of Sociology, UCLA, UC Los Angeles

Ragin, C. (2008). Redesigning Social Inquiry. Chicago, IL: University of Chicago Press

Rihoux, B. \& Ragin, C. (2009). "Introduction." In Rihoux, B. \& Ragin, C. (eds.) Configurational Comparative Methods: Qualitative Comparative Analysis (QCA) and Related Techniques (pp: xvii-xxv). Thousand Oaks, US: SAGE Publications

Rorty, R. (1979). Philosophy and the Mirror of Nature. New Jersey, US: Princeton University Press

Smith, S. (1996). "Positivism and Beyond."
In S. Smith, K. Booth \& M. Zalewski (Eds.) International Theory: Positivism and Beyond (pp. 11-44). Cambridge, UK: Cambridge University Press

Smithson, M. \& Verkuilen, J. (2006). Fuzzy Set Theory: Applications in the Social Sciences. London, UK: SAGE Publications

Talisse, R. \& Aikin, S. (2011). Introduction. In R. Talisse \& S. Aikin (Eds.) The Pragmatism Reader (pp. 4-11). New Jersey, US: Princeton University Press

Tavory, I. \& Timmermans, S. (2014). Abductive Analysis: theorizing qualitative research. Chicago: University of Chicago Press

Uebel, T. (2014). "Logical Empiricism.", in M. Curd, \& S. Psillos, The Routledge Companion to Philosophy of Science. Second Edition (pp. 90-103). New York, US: Routledge

Viskovatoff, A. (2004). "A Deweyan Economics Methodology." Pp. 271303, in Khalil, E. (ed.), Dewey, Pragmatism, and Economic Methodology. New York: Routledge

Waugh, J. \& Ariew, R. (2008). "The History of philosophy and the philosophy of science. In M. Curd \& S. Psillos (Eds.), The Routledge Companion to Philosophy of Science (pp. 2738). Second Edition. New York, US: Routledge 
